\title{
ロボットマニピュレータの非線形適応 $H_{\infty}$ 制御*
}

宮里 義彦

\author{
Nonlinear Adaptive $H_{\infty}$ Control for Robotic Manipulators*
}

Yoshihiko MIYASATO $^{\dagger}$

\section{1. 緒言}

近年, 逆最適化の観点に立って, 漸近安定であるだけ でなく特定の評価関数に対して最適あるいは準最適とな るような非線形制御系や適応制御系の構成に関する研 究が行われている $[1-5]$.これに関連して，本速報では 逆最適化に基づくロボットマニピュレータの非線形適応 $H_{\infty}$ 制御について論じる．提案する手法では，外乱とシ ステムパラメータの推定誤差を $H_{\infty}$ 制御問題の外乱と見 なし [5], 外乱から入力項も含む一般化出力への $\mathcal{L}_{2}$ ゲイ ンを規定する。このため通常の外乱だけでなくパラメー 夕の推定誤差にロバストな非線形適応制御系が構成され る.なお同様の問題を扱ったものに $[6,7]$ があるが, 本 速報ではパラメー夕誤差を外乱項に含めて設計する点で, $[6,7]$ を包含した結果になっている.

\section{2. 問題設定}

$n$ 自由度のロボットマニピュレータを考える。

$$
M(\theta) \ddot{\theta}+C(\theta, \dot{\theta}) \dot{\theta}+G(\theta)=\tau+d
$$

ただし $\theta \in \mathbf{R}^{n}$ は関節角, $M(\theta) \in \mathbf{R}^{n \times n}$ は慣性行列, $C(\theta, \dot{\theta}) \in \mathbf{R}^{n \times n}$ はコリオリ・遠心力項, $G(\theta) \in \mathbf{R}^{n}$ は重 力項, $\tau$ は入力トルク (制御入力),$d$ は外乱とする. $M(\theta), C(\theta, \dot{\theta}), G(\theta)$ に含まれるシステムパラメータと 外乱 $d$ は未知とし, $\theta, \dot{\theta}$ および $\tau$ は測定可能とする. 回 転型のロボットマニピュレータには次の性質がある [8].

(1) $M(\theta)$ は有界で正定対称行列である.

(2) $\dot{M}(\theta)-2 C(\theta, \dot{\theta})$ は歪み対称行列である.

(3) (1) 式の右辺は以下の形式に書かれる.

$$
M(\theta) a+C(\theta, \dot{\theta}) b+G(\theta)=\Omega(\theta, \dot{\theta}, a, b)^{\mathrm{T}} \Phi
$$

\footnotetext{
* 原稿受付 2005 年 1 月 12 日

†統計数理研究所 予測制御研究系 Department of Prediction and Control, The Institute of Statistical Mathematics; Minami-Azabu, Minato-ku, Tokyo 106-8569, JAPAN
}

Key Words: adaptive control, nonlinear control, $H_{\infty}$ control, robotic manipulator.
ただし $\Omega(\theta, \dot{\theta}, a, b)$ は $\theta, \dot{\theta}, a, b$ に関する既知の関

数であり, $\Phi$ は未知のシステムパラメータである. 制御目的は, 関節角 $\theta$ が望ましい規範信号 $\theta_{d}$ に追従しつ つ, 同時に特定の $H_{\infty}$ 制御特性が実現されるように, 制 御入力 $\tau$ を適切に決定することである.

\section{3. 目標值追従制御系}

目標値追従制御系の基本構成 $[6,9]$ を示す. 目標軌道 $\theta_{d}$ に対する追従誤差信号を

$$
e \equiv \theta-\theta_{d}, \quad s \equiv \dot{e}+\lambda e \quad(\lambda>0)
$$

のように定めて，入力トルク $\tau$ を次のように発生させる.

$$
\begin{aligned}
& \tau=\Omega(\theta, \dot{\theta}, a, b)^{\mathrm{T}} \hat{\Phi}-e+v \\
& a \equiv \ddot{\theta}_{d}+\lambda^{2} e-\lambda s, \quad b \equiv \dot{\theta}_{d}-\lambda e
\end{aligned}
$$

ただし $\hat{\Phi}$ は未知パラメータ $\Phi$ の推定值で， $v$ は後に定め る安定化信号である.これに対して正定関数 $V$ を定めて

$$
V=\frac{1}{2} s^{\mathrm{T}} M(\theta) s+\frac{1}{2}\|e\|^{2}
$$

マニピュレータの性質の (1), (2), (3) に着目して軌道に 沿って時間微分すると次式を得る。

$$
\begin{aligned}
\dot{V} & =-\lambda\|e\|^{2}+s^{\mathrm{T}} v+s^{\mathrm{T}} d+s^{\mathrm{T}} \Omega(\theta, \dot{\theta}, a, b)^{\mathrm{T}} \tilde{\Phi} \\
\tilde{\Phi} & \equiv \hat{\Phi}-\Phi
\end{aligned}
$$

ただし $a$ と $b$ の定義は (5) 式によるものとする.

\section{4. 非線形適応 $H_{\infty}$ 制御}

提案する非線形適応 $H_{\infty}$ 制御について述べる。まず 適応則を特に規定しない非線形 $H_{\infty}$ 制御について論じ, 次に $\hat{\Phi} の$ 調整に射影型適応則を用いた非線形適応 $H_{\infty}$ 制 御を述べる.どちらの制御方式も制御系の有界性が保証 され, 特定の $H_{\infty}$ 制御性能が達成される。

\section{1 非線形 $H_{\infty}$ 制御}

本節では $\hat{\Phi}$ は任意の有界な設計パラメータとする. 提 案する非線形 $H_{\infty}$ 制御方式は $d$ とパラメータ推定誤差 $\tilde{\Phi}$ を外乱と見なす $H_{\infty}$ 制御問題の解として導出される [5]. 
このために次の仮想システムを導入する.

$$
\begin{aligned}
& \dot{x}=f(x)+g_{11}(x) d+g_{12}(x) \tilde{\Phi}+g_{2} v \\
& x=\left[\begin{array}{l}
e \\
s
\end{array}\right], f(x)=\left[\begin{array}{c}
-\lambda e \\
-M^{-1} C s
\end{array}\right] \\
& g_{11}(x)=g_{2}(x)=\left[\begin{array}{c}
0 \\
M^{-1}
\end{array}\right] \\
& g_{12}(x)=\left[\begin{array}{c}
0 \\
M^{-1} \Omega^{\mathrm{T}}
\end{array}\right]
\end{aligned}
$$

仮想システム $(9),(10)$ の軌道に沿って $V(6)$ を時間微分 すると (7) が得られることに注意する.この仮想システ ムに対して次式の Hamilton-Jacobi-Issacs 方程式（HJI 方程式）を考え，解 $V$ を(6) 式で与える.

$$
\begin{aligned}
& \frac{\partial V}{\partial t}+\mathcal{L}_{f} V \\
& +\frac{1}{4}\left\{\frac{\left\|\mathcal{L}_{g_{11}} V\right\|^{2}}{\gamma_{1}^{2}}+\frac{\left\|\mathcal{L}_{g_{12}} V\right\|^{2}}{\gamma_{2}^{2}}-\mathcal{L}_{g_{2}} V R^{-1}\left(\mathcal{L}_{g_{2}} V\right)^{\mathrm{T}}\right\} \\
& +q(x)=0
\end{aligned}
$$

ただ $q(x)$ は正值の関数， $R$ は正定対称行列であり，逆 最適化の観点から, HJI 方程式 (11) より, 解 $V(6)$ と 正定数 $\gamma_{1}, \gamma_{2}$ に対して求められる. 解 $V(6)$ をHJ方程 式 (11) に代入すると以下の式が得られる.

$-\lambda\|e\|^{2}+\frac{\|s\|^{2}}{4 \gamma_{1}^{2}}+\frac{s^{\mathrm{T}} \Omega^{\mathrm{T}} \Omega s}{4 \gamma_{2}^{2}}-\frac{1}{4} s^{\mathrm{T}} R^{-1} s+q(x)=0$

これより正值の関数 $q(x)$ と正定行列 $R$ は

$$
\begin{aligned}
& q=\lambda\|e\|^{2}+\frac{1}{4} s^{\mathrm{T}} K s \\
& R=\left(\frac{1}{\gamma_{1}^{2}} I+\frac{1}{\gamma_{2}^{2}} \Omega^{\mathrm{T}} \Omega+K\right)^{-1},\left(K=K^{\mathrm{T}}>0\right)
\end{aligned}
$$

のように求められる. また入力信号（安定化信号） $v$ は対 応する $H_{\infty}$ 制御問題の解として次のように決定される.

$$
\begin{aligned}
v & =-\frac{1}{2} R^{-1}\left(\mathcal{L}_{g_{2}} V\right)^{\mathrm{T}}=-\frac{1}{2} R^{-1} s \\
& =-\frac{1}{2}\left(\frac{1}{\gamma_{1}^{2}} I+\frac{1}{\gamma_{2}^{2}} \Omega^{\mathrm{T}} \Omega+K\right) s
\end{aligned}
$$

この時，もとの制御対象 (1) に対して定理 1 が成立する.

【定理 1】 (4)，(5)，(15) から構成されるロボットマ ニピュレータ (1)の非線形制御系は, 任意の有界な設計 パラメータ $\hat{\Phi}$ と任意の有界外乱 $d$ に対して, 有界となる. また $v$ は以下の評価関数 $J$ を最小化する最適制御入力で ある。

$$
\begin{aligned}
J= & \sup _{d, \tilde{\Phi} \in \mathcal{L}^{2}}\left\{\int_{0}^{\mathrm{T}}\left(q+v^{\mathrm{T}} R v\right) d \tau+V(t)\right. \\
& \left.-\gamma_{1}^{2} \int_{0}^{\mathrm{T}}\|d\|^{2} d \tau-\gamma_{2}^{2} \int_{0}^{\mathrm{T}}\|\tilde{\Phi}\|^{2} d \tau\right\}
\end{aligned}
$$

さらに次の不等式が成立する。

$$
\begin{aligned}
& \int_{0}^{\mathrm{T}}\left(q+v^{\mathrm{T}} R v\right) d \tau+V(t) \\
& \quad \leq \gamma_{1}^{2} \int_{0}^{\mathrm{T}}\|d\|^{2} d \tau+\gamma_{2}^{2} \int_{0}^{\mathrm{T}}\|\tilde{\Phi}\|^{2} d \tau+V(0)
\end{aligned}
$$

（証明）HJI 方程式 (11)，(12) を考慮すると $\dot{V}$ が以下 のように評価される。

$$
\begin{aligned}
\dot{V}= & \left(v+\frac{1}{2} R^{-1} s\right)^{\mathrm{T}} R\left(v+\frac{1}{2} R^{-1} s\right)-v^{\mathrm{T}} R v \\
& -\gamma_{1}^{2}\left\|d-\frac{s}{2 \gamma_{1}^{2}}\right\|^{2}+\gamma_{1}^{2}\|d\|^{2} \\
& -\gamma_{2}^{2}\left\|\tilde{\Phi}-\frac{\Omega s}{2 \gamma_{2}^{2}}\right\|^{2}+\gamma_{2}^{2}\|\tilde{\Phi}\|^{2}-q
\end{aligned}
$$

これより $v(15)$ が $J$ の最適解であることと，不等式 $(17)$ の成立が示される.また $(15)$ を(18) に代入すると

$$
\dot{V} \leq-q-v^{\mathrm{T}} R v+\gamma_{1}^{2}\|d\|^{2}+\gamma_{2}^{2}\|\tilde{\Phi}\|^{2}
$$

が得られることから, 制御系の有界性も示される.

（注意 1）提案する制御方式 (15)において $\gamma_{2} \rightarrow \infty$ と すると, 通常の適応 $H_{\infty}$ 制御で用いられる制御則と同じ 構造になり $[6,7]$, 外乱 $d$ から一般化出力 $\sqrt{q+v^{\mathrm{T}} R v}$ へ の $\mathcal{L}_{2}$ ゲインが規定される. また $\gamma_{1}, \gamma_{2} \rightarrow \infty$ とすると， $\int_{0}^{\mathrm{T}}\left(q+v^{\mathrm{T}} R v\right) d \tau$ を評価関数とする最適制御問題の解と なるが，得られる制御則は通常の適応制御で用いられる ものと同じ形式になる $[6,9]$.

\section{2 非線形適応 $H_{\infty}$ 制御}

次に設計パラメータ $\hat{\Phi}$ を適応的に決定する適応 $H_{\infty}$ 制御方式について述べる. $d(\neq 0)$ に対応して, 以下の射 影型適応則 $[10]$ を導入する。

$$
\begin{aligned}
& \text { if }\|\hat{\Phi}(t)\|=N_{\Phi} \& \hat{\Phi}(t)^{\mathrm{T}} \Gamma \Omega(t) s(t)<0 \\
& \qquad \dot{\hat{\Phi}}(t)=-\Gamma \Omega(t) s(t)+\Gamma \frac{\hat{\Phi}(t) \hat{\Phi}(t)^{\mathrm{T}}}{\hat{\Phi}(t)^{\mathrm{T}} \Gamma \hat{\Phi}(t)} \Gamma \Omega(t) s(t) \\
& \text { otherwise } \\
& \quad \dot{\hat{\Phi}}(t)=-\Gamma \Omega(t) s(t)
\end{aligned}
$$

ただし $\|\Phi\| \leq N_{\Phi},\|\hat{\Phi}(0)\| \leq N_{\Phi}$ であり， $N_{\Phi}$ は既知と する.すると以下の $W$

$$
W=V+\frac{1}{2} \tilde{\Phi}^{\mathrm{T}} \Gamma^{-1} \tilde{\Phi}
$$

に対して $\dot{W}$ が以下のようになる（不等号は射影の操作 のため).

$$
\dot{W} \leq-\lambda\|e\|^{2}+s^{\mathrm{T}} v+s^{\mathrm{T}} d
$$

これは $\tilde{\Phi}=0$ とおいた仮想システム $(9),(10)$ に対応す る.したがって 4.1 と同様の論法により, $v(15)$ および 適応則 $(20)$ に対して次の定理が導かれる.

【定理 2】 (4), (5), (15), (20)より構成されるロボッ トマニピュレータ (1) の非線形適応制御系は, 任意の有 界な外乱 $d$ に対して有界となる。 また $v$ は以下の評価関 数 $J$ の上界を最小化する準最適制御入力になる. 


$$
\begin{aligned}
J= & \sup _{d \in \mathcal{L}^{2}}\left\{\int_{0}^{\mathrm{T}}\left(q+v^{\mathrm{T}} R v\right) d \tau+W(t)\right. \\
& \left.-\gamma_{1}^{2} \int_{0}^{\mathrm{T}}\|d\|^{2} d \tau\right\}
\end{aligned}
$$

さらに次の不等式も成立する.

$$
\begin{aligned}
\int_{0}^{\mathrm{T}}(q & \left.+v^{\mathrm{T}} R v\right) d \tau+W(t) \\
& \leq \gamma_{1}^{2} \int_{0}^{\mathrm{T}}\|d\|^{2} d \tau+W(0)
\end{aligned}
$$

とくに $d \in \mathcal{L}^{2}$ のときは, 追従誤差 $e, s$ は零に収束する.

$$
\lim _{t \rightarrow \infty} e=\lim _{t \rightarrow \infty} s=0
$$

（証明）射影型適応則により $\hat{\Phi} \in \mathcal{L}^{\infty}$ が成立する。し たがって定理 1 より適応系の有界性が保証される。vの 準最適性と $(24)$ は，(18)において $\tilde{\Phi}, V$, 等号をそれぞれ $0, W$, 不等号に置き換えることで，容易に導かれる.

(注意 2) 提案する適応制御系においては定理 1 も成 立するので，パラメー夕推定誤差 $\tilde{\Phi} に$ 対してロバストと なり，少ない制御コストで良好な過渡特性が得られる。

(注意 3) 提案する適応制御手法は類似の非線形ダン ピング項が使われている点で [11] の研究に密接な関係が ある. しかし本稿の手法は特定の $H_{\infty}$ 制御問題の解とし て導出され，制御項も評価に加えられている点が異なる.

\section{5. 数值例}

手法の有効性を確認するために SICE-DD アーム（2 自由度) のデー夕（Table 1）を用いて数值実験を行った。

\begin{tabular}{lll} 
Table 1 & Physical parameters \\
\hline \hline Link $(i)$ & 1 & 2 \\
\hline$m_{i}[\mathrm{~kg}]$ & 12.27 & 2.083 \\
\hline$I_{i}\left[\mathrm{~kg} \cdot \mathrm{m}^{2}\right]$ & 0.1149 & 0.0144 \\
\hline$l_{i}[\mathrm{~m}]$ & 0.2 & 0.2 \\
\hline$r_{i}[\mathrm{~m}]$ & 0.063 & 0.080 \\
\hline
\end{tabular}

マニピュレータの目標軌道は次式で表される $(0 \leq t \leq 1)$.

$$
\theta_{d 1}(t)=6 \pi \cdot\left(\frac{1}{2} t^{2}-\frac{1}{3} t^{3}\right), \theta_{d 2}(t)=\pi-2 \theta_{d 1}(t)
$$

パラメー夕推定誤差に対する結果の比較を行うために $d=0$ と設定した．設計パラメータは以下のように選んだ.

$$
\Gamma=I, \quad \lambda=1, \quad K=I, \quad N_{\Phi}=50, \quad \hat{\Phi}(0)=0
$$

数值実験は次の三つのケースについて行った.

- Case 1: 通常の適応制御 $[6,9]\left(\gamma_{1}, \gamma_{2} \rightarrow \infty\right)$

- Case 2: 通常の適応 $H_{\infty}$ 制御 $[6,7] \quad\left(\gamma_{1}=0.1, \gamma_{2} \rightarrow\right.$ $\infty)$

- Case 3: 提案法 $\left(\gamma_{1}=0.1, \gamma_{2}=0.1\right)$

結果を Table 2 に示す $\left(\|e(\cdot)\|^{2} \equiv \int_{0}^{1}\|e(t)\|^{2} d t,\|\tau(\cdot)\|^{2} \equiv\right.$ $\left.\int_{0}^{1}\|\tau(t)\|^{2} d t\right)$. Case 3 の場合が, 最も少ない制御入力
で一番良好な追従特性が得られていることがわかる．具 体的な応答結果を調べると, Case 1 と Case 2 の場合に 入力トルクが振動的に変化するのに対し, Case 3 の場合 は入力トルクが振動的にならずに良好な特性が得られた。

Table 2 Simulation results

\begin{tabular}{llll}
\hline \hline & Case 1 & Case 2 & Case 3 \\
\hline$\|e(\cdot)\|^{2}$ & $0.45948 \mathrm{E}-02$ & $0.25992 \mathrm{E}-02$ & $0.54750 \mathrm{E}-03$ \\
\hline$\|\tau(\cdot)\|^{2}$ & $0.62115 \mathrm{E}+01$ & $0.55803 \mathrm{E}+01$ & $0.46626 \mathrm{E}+01$ \\
\hline
\end{tabular}

\section{6. 結言}

ロボットマニピュレータに対する非線形適応 $H_{\infty}$ 制御 系の構成法について述べた. 提案する手法は, 外乱とパ ラメータの推定誤差を等価的な外乱と見なした $H_{\infty}$ 制御 問題の解として導出される. 数值実験の結果 (Table 2) から, 提案する手法 (Case 3) が通常の適応制御 (Case 1）や通常の適応 $H_{\infty}$ 制御（Case 2) と比較して，ょり 少ない制御コストでより良好な過渡特性を有しているこ とがわかる。これは適応パラメータの誤差を外乱と見な した $H_{\infty}$ 制御の外乱抑制効果と, 制御入力（安定化信 号) が対応する $H_{\infty}$ 制御問題の評価関数に含まれている ためと考えられる.

\section{参 考文献}

[1] M. Krstić and H. Deng: Stabilization of Nonlinear Uncertain Systems, Springer (1998)

[2] 宮里：逆最適性に基づく非線形 $\mathcal{H}_{\infty}$ 制御; 計測と制御, Vol. 39, No. 2, pp. 112-118 (2000)

[3] 宮里: 適応 $\mathcal{H}_{\infty}$ 制御系の構成法; 計測と制御, Vol. 40, No. 10, pp. 692-697 (2001)

[4] 宮里: 最適性に基づく適応制御系の再設計; 計測自動制 御学会論文集, Vol. 38, No. 9, pp. 765-774 (2002)

[5] 宮里: パラメー夕を外乱と見なした非線形適応 $\mathcal{H}_{\infty}$ 制御 系の構成法; 計測自動制御学会論文集, Vol. 39, No. 10, pp. 914-923 (2003)

[6] 佐藤, 渡辺: 逆最適性に基づくロボットシステムの適応 型 $H^{2}, H^{\infty}$ 制御 ; 第 23 回 Dynamical System Theory シンポジウム資料, pp. 369-372 (2000)

[7] 佐藤：最適性を考慮したロボットシステムの適応型 $H^{\infty}$ 制御 -設計の自由度についての考察; 第 1 回制御部門大 会資料, pp. 587-590 (2001)

[8] M. W. Spong and M. Vidyasagar: Robot Dynamics and Control, John Wiley \& Sons (1989)

[9] 申, 田村: ロボットシステムのロバスト軌道追従制御 消散性理論からのアプローチ- ; 計測自動制御学会論文 集, Vol. 35, No. 3, pp. 326-332 (1999)

[10] P. A. Ioannou and J. Sun: Robust Adaptive Control, PTR Prentice-Hall (1996)

[11] P. Tomei: Robust adaptive control of robots with arbitrary transient performance and disturbance attenuation; IEEE Trans. Autom. Control, Vol.44, pp. 654-658 (1999) 